\title{
A Theoretical Study on English Teaching in Chinese Ethnic Minority Regions
}

\author{
Huang Jian ${ }^{1}$ \\ ${ }^{1}$ School of Foreign Languages, Leshan Normal University, China \\ Correspondence: Huang Jian, School of Foreign Languages, Leshan Normal University, Leshan, Sichuan, China. \\ Tel: 86-138-9066-3663. E-mail: shaominmatt@sina.com
}

Received: May 9, 2013 Accepted: May 30, 2013 Online Published: June 17, 2013

doi:10.5539/elt.v6n7p168 URL: http://dx.doi.org/10.5539/elt.v6n7p168

This research is financed by the Research Projects of Leshan Normal University (No. S1146), Sichuan Foreign Language Literature Research Center and Shanghai Foreign Language Education Press. (No. SCWYH12-12)

\begin{abstract}
From an investigation about the factors influencing the trilingual education in Chinese ethnic minority regions, the author find out that the minority students are incompetent in English learning. Inappropriate teaching strategies, learning materials as well as language policy hinder the development of teaching and learning progress in those areas, which still causes the minority students' lack of learning motivation. In trilingual education, we believe that teaching should be learner-centered and teachers, students, tasks and context of situation are greatly emphasized. This paper conducts a research on English teaching in trilingual education based on the application of motivation, communicative competence and autonomous learning theories in Chinese minority regions, looking forward to provide some approaches on improving the minority students' English learning competence.
\end{abstract}

Keywords: trilingual education, Motivation Theory, Communicative Competence Theory, autonomous learning, minority students

\section{Introduction}

\subsection{The Trilingual Education in China}

With the development of the economic globalization, English has become a major communicational tool all over the world. In Chinese minority regions, it is necessary for minority students to receive trilingual education. Namely, the minority students must learn their minority languages, standard Chinese and English. In this paper, trilingual education indicates the English teaching in ethnic minority regions in China.

But the unbalanced distribution of education resource, the shortage of professional English teachers and the limitation of English learning materials, courses English learning quite difficult for the minority students. From the author's survey of trilingual education in Leshan Ebian Yi Autonomous County, minority students are incompetent in English communication, which contributes great influence on the minority students' interest of learning English. The trilingual education materials are not attractive since the textbooks and teaching methods are commonly designed in bilingual educational approaches. Still, there are no specific trilingual educational strategies to each nationality in policy-making.

\subsection{The Attitude of the Minority Students to Trilingual Education}

English instruction in ethnic minority regions has not received a deserved treatment as required, for the English teaching contents could not satisfy the pupils' thirsts for knowledge, which is contributed of their different cultural background. It is obvious that the students' ideological knowledge systems are constructed from their ethnic culture and family education. From the author's survey, currently, the attitude of the minority students to trilingual education is badly influenced, which can be manifested as:

1. Nearly all the students prefer Chinese while many of them feel exhausted in English learning. And they all neglect their ethnic language learning because they think that it is not widely used in their daily life and it is not helpful to the College Entrance Examination. 
2. The minority students could not be attracted by the trilingual education Textbooks and teaching methods.

3. Many minority students claim that English is widely used as some international language but they don't need to learn it well. The indifferent attitude to English learning influences the English teaching greatly.

Drawbacks above leave English instruction in ethnic minority regions in a predicament. The malpractices of the policy-making as well as the teaching designing, however, have hampered students to master the necessary speaking and listening skills. Definitely, it is necessary to apply constructivism theory into English teaching in trilingual education as long as teachers have a comprehensive understanding of the interrelation between constructivism and English communicative competence.

\section{Problems in Present Trilingual Education in Ethnic Minority Regions}

When learning some foreign language, bilinguals are more pragmatic functional and productive than monolinguals (Jorda M. P. S, 2005). But it is obvious that ethnic minority students fail in competing Han students in English learning. Based on the surveys from some researchers (Li Xiaohong, 2010; Liu Quanguo, 2007), several issues on trilingual education are listed: psychological barrier, context barrier and cultural conflict. The issues could be summarized as following:

\subsection{Issues on Psychological Barrier}

Essentially, the issues on trilingual education can be divided into two parts, internal problems and external problems. Internal problems are caused by the pupils themselves. We believe that pupils can build up their awareness of English learning once they discover their internal shortcomings.

The Clerk couple believed that anxiety, fear, hesitation and other psychological phenomenon would interfere with speech and the plan issued by the whole process, and made impact on second language fluency directly (Clerk H., Clerk E., 1977: 168). Schmidt divided anxiety of foreign language into three types, that were, fear of exchange, the fear of negative evaluation (their language ability judged by others), and test anxiety (Schmidt, 1992: 63). According to Clerk couple's theory, people who are fluent in the language are often considered more intelligence that others, more capable and more efficient, which evidence the surveys, mentioned above: more than $80 \%$ minority pupils are affected by psychological barriers.

Based on the author's class-room observation in Ebian Yi Autonomous County, the psychological barriers affecting English learning are drawn in three aspects: psychological tension, psychology of inferiority and psychology of being afraid of difficulty. Pupils are worried about making faults in class, and then being ridiculed. Holders of such psychology perform as: daring not to face to others, speaking with trembling voice, intermittently.

These psychological issues cause pupils' lack of interest, confidence and self-realization. Albert Einstein says that: Interest is the best teacher. For the lack of intense and continuous interest, pupils are not likely to experience the joy and pleasure of English learning which can motivate them to keep high enthusiasm and zeal. For instance, it is a common phenomenon in Chinese ethnic minority regions that pupils learn English in large-sized class. Many of them may feel bored to the teaching contents and then fall into sleep in class. But teachers do not have energy and time to care about their pupils. Only a few of the pupils could be capable of keeping up with the teaching contents. Therefore, pupils' lack of interest hinders their English learning with the guidance of their teachers, let alone expecting them to learn English autonomously. Then, our pupils lose their best teacher who can stimulate them in English learning and encourage their learning autonomously.

The pupils who are devoid of learning motivation will be lack of confidence to control their emotions. The pupils with low confidence tend to feel doubt, failure, disappointment or independence to their ability. The pupils' intrinsic motivation and extrinsic motivation is changeable (Hong Hu, 2000: 68). The more inferior the pupil sense to others, the more hopeless they feel. For instance, from an English class the author observed, those without self-confidence may feel it hard to comment on a topic from their teacher, and were likely to perform poorly and awkwardly in responding to their teacher's assignment.

In China, the National English Curriculum Standards carried out in 2001. It is designed to promote Chinese pupils' overall quality, but the author believes that these standards were designed without considering the status of minority pupils. Because they are lack of interest and confidence in English learning, including lack of teaching resources, many minority pupils can not meet the high learning goals designed according to the National English Curriculum Standards. And then, the trilingual education could not encourage the self-realization of the pupils.

From the discuses above, we may draw the issues on psychological barrier as: 


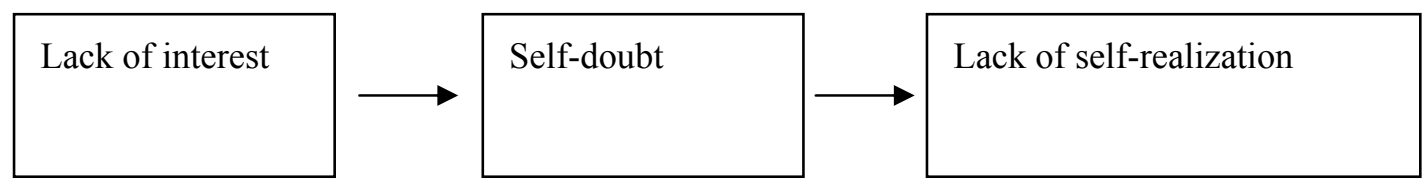

Figure 1.

\subsection{Issues on Context Barrier}

It is well known that mother-tongue acquisition is achieved in a real, high-density and high-intensity environment of the language, so it is much easily and naturally to master the native language. In some proper context, anxiety, fear and other psychological factors can be adjusted to a satisfactory level. Compared with the mother tongue, the context problem is another barrier to the second language acquisition.

Because of the unbalanced education resource distribution, minority pupils' indifferent attitude towards English learning and the some incorrect English teaching approaches, it is hard to establish a suitable SLA context in ethnic minority regions.

\subsection{Issues on Cultural Conflict}

Language is rooted in the culture, and also the carrier of culture. Different social environment and background bring a lot of obstacles to cross-cultural communication. Minority pupils strongly accept the trilingual education while they ignore other cultural customs. The original culture and western culture are not acceptable in the ethnic minority autonomous counties because of their ethnologic self-respect. In trilingual classroom, the pupils always show scant respect to any other culture introduction except their own. There are three different types of national amalgamation: national combination, national integration and national assimilation. We suppose that minority pupils and their families may misunderstand the Chinese language policy. They are afraid of the national assimilation and take the cultural instruction as some cultural invasion.

\subsection{Research Questions}

The purpose of this study is to present the theories in English teaching in ethnic minority regions, in order to set up a theoretical foundation of trilingual education and look forward to contribute to the establishment of trilingual education models in ethnic minority regions in China. From the analysis above, we draw a conclusion that the weak points in nowadays trilingual education center on three aspects: learning motivation, learning strategies and cultural conflict. So this research mainly focuses on the following research questions:

(1) How to inspire pupils' interest toward English learning?

Interest inspiration must be the key to the contribution of the solution to psychological barrier.

(2) How to improve English learner autonomy?

There is no prerequisite for English teachers to construct suitable English context in classroom because of the lack of education resources. So, to stimulate pupils learning English after class must be a supplementary to the classroom teaching. Hence, the pupils should learn how to learn.

(3) How to improve pupils' communicative competence?

To reverse the pupils' misunderstanding to the cultural instruction, we must enrich the teaching contents and drive the idea that English learning must be the necessary way to carry forward their culture in the world. It might work to promote pupils to introduce their ethnologic culture in English. The minority pupils may gradually accept the multi-culture education. To reach the goal, pupils' communicative competence must be improved.

\section{Interpretation of the Applied Theories}

The analysis in the first two parts tells the current situation of English teaching in ethnic minority regions. Generally speaking, it is assumed that the following theories will come to be assistance to English educators to create theoretical foundation to trilingual education in China.

\subsection{An Introduction to Motivation Theory}

Motivation refers to the combination of a good attitude to learn the language and the determination to achieve a goal (Gardner, 1985). Gardner and Lambert established a social educational model which enters on four classes of variables: the social milieu, individual differences, language acquisition contexts and outcomes. Gardner's classical model has been expanded in light of psychological theories of a broader range (Ellis, 1994). Teaching 
strategies should be in tune with the perceptions of English teachers. Then, to dominate the motivation theories, Dornyei put forward three-level categorization which includes: language standard, learner standard and learning situation standard (Dornyei, 1998). Educators should spur the learners to pursue the sense of achievement and self-confidence.

To define the function of motivation theory, it enhances individual's internal power with internal desire and external power with reality purposes. According to this definition, English educators always motivate learners' positive attitude towards the target language as well as drawing the potential practical benefits from the target language proficiency.

\subsection{An Introduction to Autonomous Learning Theory}

The term, learner autonomy, could be traced back to the 1980s. It is a theory of learning which appears with the rise of cognitive psychology and humanism psychology and also has other designations such as: autonomous learning, self-directed learning, self-access learning, self-monitoring, self-instruction, independence, langue awareness, self direction and independent learning (Hedge, 2000). There is no unique model to define learner autonomy.

Learner autonomy firstly put forward by Holec in 1980s, who defines autonomy as the ability to take charge of one's own learning, which is not inborn but must be acquired either by natural means or formal learning, in a systematic, deliberate way (Holec, 1981). Huttunen states: A learner is fully autonomous when he is working individually or in group, taking responsibility for the planning, monitoring and evaluation of his studies (Huttunen, 1986). Littlewood defines learner autonomy as: one who has an independent capacity to make and carry out the choices which govern his or her actions (Littlewood, 1996). Scholars have come to an agreement on the point of the capability of learning independently instead of being forced by others.

English autonomous learning has been highly thought of by the experts in EFL teaching. In Chinese ethnic minority regions, pupils fail to have an authentic English learning environment or context. From the author's survey, they do not use English either in class or in their daily life. They show the attitude that there is no necessity to communicate with others in English. Therefore, it is quite difficult for pupils to learn English well in ethnic minority regions where there is no access to English communication. What's worse, big sized classroom teaching could be the only choice in minority areas because of the shortage of education resources. Consequently, English learning autonomy must be a necessary supplementary in trilingual education.

\subsection{An Introduction to Communicative Competence}

The concept of communicative competence was put forward by Dell Hyme in 1972. According to Dell Hyme (Hyme, 1972:34), in language teaching, especially in communicative language teaching, communicative competence is often used to describe the goal of language teaching. Communicative competence refers to the ability not only to apply the grammatical rules of a language in order to form grammatically correct sentences but also to know when, where and to whom to use these sentences. Competent speakers of a language should know what to say, to whom, and how to say it. The communicatively competent language user knows how to make appropriate choices of words and structures to fit the situation in which communication occurs. Communicative competence is the ability to use the language system appropriately in any circumstances, with regard to the functions and the varieties of language.

It is important to cultivate and strengthen minority pupils' communicative competence to make successful cross-cultural communication and to spread their ethnic culture to the outside world.

In 1980s, Michael Cnale and Merril Swain identified four dimensions of communicative competence (Michael Cnale, Merril Swain, 1980: 47). They are grammatical competence, discourse competence, sociolinguistic competence and strategic competence. The first two dimensions reflect the usage of linguistic system while the last two define the functional aspects of communication. Communicative competence refers to both knowledge and skill in using this knowledge when interacting in actual communication. Grammatical competence is concerned with mastery of the language code itself. Discourse competence, the complement of grammatical competence in many ways, concerns mastery of how to combine grammatical forms and meanings to achieve a unified spoken or written text in different types. Sociolinguistic competence is the knowledge of the cultural rules of language and discourse. Strategic competence, a construct that is exceedingly complex, refers to the strategies that communicators employ to initiate, terminate, maintain, repair, and redirect communication.

\section{Discussions}

To solve the problems in present trilingual education in minority-area high schools, we concentrate on solutions of the three questions summarized above under the guidance of motivation, learner autonomy and 
communicative competence theories.

\subsection{How to Inspire Pupils' Interest toward English Learning?}

We attribute the occurred psychological barriers to pupils' lack of interest to English learning. Based on the motivation theory, teaching strategies could be listed as follows:

\subsubsection{Setting up Learning Targets to Satisfy the Pupils' Sense of Achievement}

It is an important teaching strategy to let pupils experience successes continuously in class. Psychologically, pupils with a successful experience will arouse the endless pursuit in mind. Namely, make full use of pupils' desire for success in the process of greater desire of success. It is teachers' duty to make sure that most of the pupils could achieve good results from the assignments and tasks. Specifically, teachers should help pupils set short-term and long-term goals in the progress of English learning. Only in this way, pupils can draw senses of achievement. Under the consideration of pupils' lack of self-realization, the pupils' goal setting must follow teachers' teaching aims, which should be designed in the principle of the realistic status of the pupils. If the learning targets were too high, frustration might be caused; if the targets were too low, complacency emotions might be aroused. In a word, appropriate learning target setting should be based on the teachers' evaluation to the actual status of pupils' English level.

\subsubsection{Exploring Effective Classroom Tasks}

The idea of task-based teaching approach is always considered as an important teaching approach in student-centered classroom teaching. Principally, tasks should be designed to motivate pupils to engage in language use. Hence, topics from the classroom tasks must be considered to cooperate to pupils' cultural background and supposed to be designed to pay attention to pupils' needs. Teachers provide rich and colorful stimulus to activate the students to learn English intelligence activities, causing the students positive learning attitude, for those activities with happy emotional experience make people satisfy with reinforcement. The humorous and positive English activities related to pupils' cultural background can really inspire pupils' interests in English learning.

Generally speaking, effective activities in trilingual education classroom should be multi-cultural, with the consideration of original, western and ethnologic culture background.

\subsubsection{Making Good Use of Feedback Information}

Pupils' learning motivation can be improved with the sense of their learning effect in time. Teachers' feedback consists of reward and punishment. With the feedback from teachers, pupils might be clear of their progress and realize their status of English level.

From the feedback information, pupils' aptitudes can be drawn as the principle of designing further learning contents. Without feedback information, teaching effect can not be timely reflected.

These strategies are supposed to joint with each other to form a circular jointed trilingual education module.

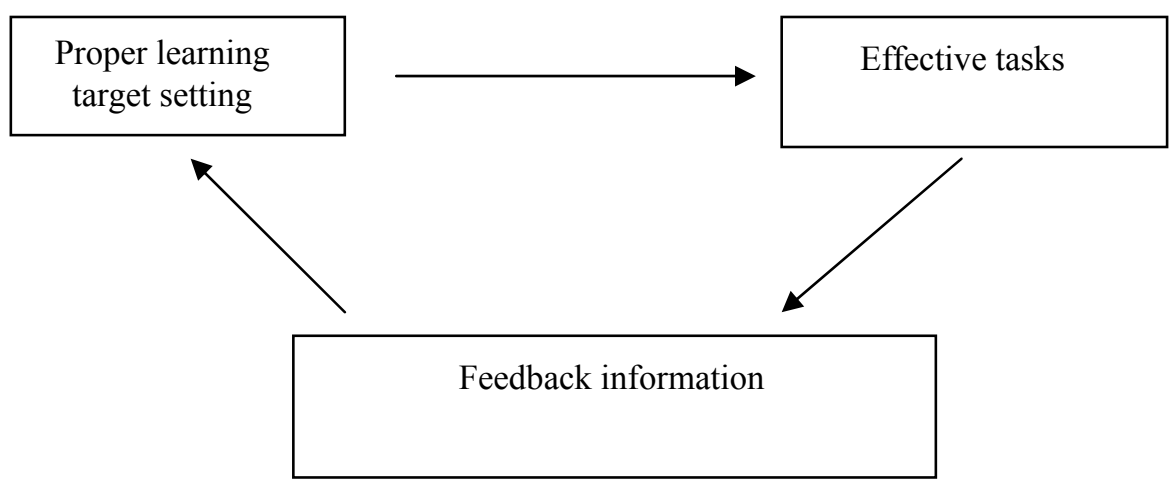

Figure 2.

\subsection{How to Improve English Learner Autonomy?}

Although the National English Curriculum Standards have already carried out the quality-oriented policy, which 
aims at improving the integrated development of the students, the implementation of this policy is not in tune with the realistic status of the pupils in ethnic minority regions. To meet such standards, pupils are required to learn more actively and independently rather than passively. It is essential to the pupils to foster learner autonomy.

\subsubsection{A Good Beginning in English Learning}

A good beginning will make pupil's latter studies easier. It is important to establish the foundation of alphabet, phonetic symbols and grammar at the very beginning. Without the steady foundation of basic English, there is no possibility for minority pupils to keep up with Han pupils in senior high school English education. As time goes by, they may feel bored in English learning and gradually be likely to give up English learning completely. Therefore, it is essential presuppositions for minority pupils to have a good beginning in English learning in order to improve English learner autonomy.

To achieve this goal, English teachers play the key role. No matter how difficult to deal with large-sized class, teachers have to measure Basic English understanding among their pupils frequently at the very beginning of English learning.

\subsubsection{Establishing English Learning Groups}

The English textbooks for the pupils adopt task-based language teaching method, and are compiled according to the National English Curriculum Standards issued by the National Ministry of Education. The textbook increases the pats of culture background, learning strategy, and self check which aims at cultivating students' learner autonomy. For the pupils in ethnic minority regions, under the situation of the lack of enough education resources, the English textbooks are usually the main materials for both teachers and students. Many teachers complain that textbooks contain larger vocabulary, grammar points and western cultural information that the pupils are not familiar with. Hence, teaching tasks are hardly carried out. In addition, some contents provide pupils opportunity of cooperation in groups. On this condition, English learning groups must be established to deal with the difficult tasks.

Learner autonomy does not mean learning alone (Pemberton, 1996). Instead, learning in a group may help a lot in promoting pupils' English. Pupils in groups cooperate in solving English tasks, in which they may experience the happiness of cooperation and dispel the feeling of loneliness. And they can supervise each other to avoid boring learning environment and self-doubt feeling.

Interests might be inspired during the cooperation. Cooperation still causes competition among the group members, and the competition could stimulate pupils' learning autonomously after class.

\subsubsection{Cooperation from the Parents}

Commonly, minority parents could not speak or use English well. Outwardly, they can hardly help their children in English learning. But definitely the parents are the key to help scheduling pupils' learning. Under the guidance of English teachers, Parents tabulate learning schedules, which can help a lot in establishing pupils' good habits of study. As the tabulators, parents should also supervise pupils how well the schedules are performing.

\subsection{How to Improve Pupils' Communicative Competence?}

From the present study, communicative competence improvement should be an approach to allay the cultural conflict among the minority pupils. So, in this study, the author does not focus on the communication practice, but creates strategies of establishing the multi-cultural environment as well as improving multi-cultural instruction in trilingual classroom.

\subsubsection{Creating a Multi-Cultural Class-Room Environment}

Communication is the purpose of language learning. Being some social behavior, language communication is rooted in culture. Minority pupils might be more likely to overcome the psychological barriers to achieve more satisfactory results if they could express themselves naturally and spontaneously in a natural and authentic language environment. Trilingual education could be carried out in an appropriate way only if the combination of language, culture and communication promotes a positive attitude of minority pupils in English learning.

Thus, the trilingual classroom environment should be set multi-culturally to satisfy to pupils' psychological knowledge system. Originally, the pupils' knowledge systems were constructed by the family education and the ethnic culture. In multi-cultural class-room, the culture background of teaching contents should be based on minority culture, and then gradually transfer from their original culture into western culture. Still, the medium of instruction must be set in minority languages at the very beginning. 


\subsubsection{Creating Trilingual Tasks for Communicative Competence}

Caused by poor pronunciation and vocabulary limitation, minority pupils are supposed to encounter difficulties in expressing their meaning successfully. Teachers may apply strategies such as circumlocution, literal translation and approximation for pupils. But to stimulate pupils' being involved into the real communication, teachers must make sure that pupils would be familiar with the topic designed in English class. Namely, teaching contents should consist of ethnologic, Chinese as well as western culture. We may define such teaching contents as trilingual tasks, but how?

Actually, there are no definite references for trilingual task creation in China. But two principles could be provided for trilingual task creation: (1) opportunities for pupils to practice English for ethnologic culture introduction; (2) multi-culture instruction in class presentation, in addition, teachers give their presentation of multi-culture with the beginning of pupils' ethnologic culture introduction in English.

\section{Conclusion}

It can be found that the psychological barriers and culture conflict exist in nowadays trilingual education. From the analysis above, this paper transfers the external issues into internal problems which are summarized in three questions.

To solve these three questions, three theories are integrated. Motivation, learner autonomy and communicative competence theories effectively meet the varied needs of the pupils amidst the multi-culture realities, and integrate teachers with theoretical approaches for trilingual education. Based on these theories, this paper put forward strategies for both trilingual teachers and minority pupils. From the perspective of pupils, learning strategies are presented as: group cooperation, parents' participation and learning target setting. From the perspective of trilingual educators, teaching strategies are also raised as: multi-cultural task creation, feedback information preparation and ethnologic culture-based instruction.

On pre-class stage, teachers should set up appropriate teaching aims to meet pupils' proper learning targets. Based on these aims, suitable teaching materials related to ethnologic and western cultures must be searched; then, multi-culture tasks could be created to pupils according to the materials. Feedbacks from the classroom tasks may help setting up new teaching aims to satisfy pupils' needs. On in-class stage, multi-cultural environment should be created based on the multi-culture tasks, which may improve pupils' communicative competence. On post-class stage, English learning groups must be established. With the cooperation from parents and teachers' evaluation to the status of pupils' assignments, group learning may effectively stimulate pupils' learning initiative. From such a teaching model, pupils' interest to English learning may be inspired and learner's autonomy as well as communicative competence can also be promoted.

The solutions to the issues on trilingual education are theoretical and empiricism. There is no practical application in trilingual education. Hence, the further studies on these issues should be concentrated on creating a teaching model based on these strategies and put the model into practice the check if it works.

\section{References}

Clerk H., \& Clerk E. (1977). Psychology and Language. New York: Harcourt Brace Jovanovich Inc.

Cnale, M., \& M, Swain. (1980). Theoretical Bases of Communicative Approaches to Second Language Teaching and Testing. Oxford: Oxford University Press.

Dornyei, Z. (1998). Motivation in Second and Foreign Language. Language Teaching, 3, 117-132.

Ellis, R. (1994). The Study of Second Language Acquisition. Oxford: Oxford University Press.

Gardner, R. (1985). Social Psychology and Second Language Learning: the Role of Attitudes and Motivation. London: Edward Arnold.

Hong Hu. (2000). Theory on Fostering Foreign Language Learning Ability. Wuhan: Hubei Education Press.

Hedge, T. (2000). Teaching and Learning in the Language Classroom. Oxford: Oxford University Press.

Holec, H. (1981). Autonomy and Foreign Language Learning. Oxford: Pegamon Press.

Huttunen, I. (1986). Towards Learner Autonomy in Foreign Language Learning in Senior Secondary School. Olou: University of Oulou.

Hyme, D. (1972). On Communicative Competence. Harmsworth: Language Education Press.

Jorda M. P. S. (2005). Third Language Learners: Pragmatic Production and Awareness. Clevedon: Multilingual Matters Ltd. 
Li Xiaohong. (2010). Tibetan Areas in Gansu Province Investigation of the Trilingual Teaching: Take a National School of Tianzhu Tibetan Autonomous County for Example. College of Education, Northwest Normal University.

Liu Quanguo. (2007). Towards EFL Teachers' Code-Switching in Trilingual Classroom. Southwest University.

Littlewood, W. (1996). An Autonomy and A Framework. System, 24(4), 427-435.

Pemberton, R. (1996). Taking Control: Autonomy in Language Learning. Hong Kong: Hong Kong University Press.

Schmidt, R. (1992). Psychological mechanisms underlying second language fluency. Studies in Second Language Acquisition, 14, 357-385.

\section{Copyrights}

Copyright for this article is retained by the author(s), with first publication rights granted to the journal.

This is an open-access article distributed under the terms and conditions of the Creative Commons Attribution license (http://creativecommons.org/licenses/by/3.0/). 